\title{
Pertumbuhan Vegetatif dan Kadar Gula Biji Jagung Manis (Zea mays saccharata, Sturt) di Pekanbaru
}

\author{
oleh: Surtinah, dan Seprita Lidar \\ Fakultas Pertanian Universitas Lancang Kuning - Pekanbaru
}

\begin{abstract}
Abstrak
Research conducted an experiment using a completely randomized design environment with four replications, and the design of treatment used is six varieties of sweet corn. Analysis of data using polynomial regression, the parameters measured were plant height, leaf number, leaf length, leaf width, and sugar beans, followed by analyzing the relationship between the growth of plants with a sugar content of sweet corn kernels. The results showed that leaf width gives a weak relationship to the sugar content of sweet corn seed, and leaf length, number of leaves and plant height had a close relationship to the sugar content of sweet corn kernels.
\end{abstract}

Keywords: varieties, sweet corn, correlation, sugar content

\section{PENDAHULUAN}

Produksi jagung manis berupa tongkol, yang akan menentukan besaran hasil yang diperoleh dari suatu proses budidaya. Faktor-faktor yang mempengaruhi pengisian bahan kering ke tongkol antara lain adalah pertumbuhan vegetatif dari tanaman tersebut. Dan organ tanaman yang memiliki peran yang paling besar adalah daun tanaman, karena daun tanaman jagung sama halnya dengan daun tanaman lain yang berfungsi untuk menghasilkan fotosintat sebagai bahan kering, yang akan ditranslokasikan ke organ yang membutuhkannya.

Penelitian-penelitian mengenai jagung manis yang sudah dilakukan di Fakultas Pertanian Universitas Lancang Kuning, belum mengamati hubungan antara organ vegetatif dan organ generatif. Melalui pnelitian ini hubungan tersebut dianalisis sehingga diperoleh gambaran yang jelas tentang sumbangan yang diberikan oleh organ vegetatatif terhadap produksi jagung manis.

Produksi biji pada tanaman yang dipangkas $1 / 2$ bagian daun di atas tongkol lebih tinggi dibandingkan tanaman yang tidak dipangkas dengan pemberian pupuk Urea yang sama. Peningkatan terjadi terhadap jumlah biji per tongkol. Berat kering biji saat panen, namun kecepatan penimbunan bahan kering semakin lambat dengan meningkatnya pupuk. Begitu juga pada waktu penimbunan bahan kering maka waktu yang terlama didapat pada tanaman yang diberi Urea 300 kg/ha (Surtinah, 2005).

Tanaman jagung manis dengan jumlah daun 10,45 menghasilkan berat tongkol tanpa kelobot 288,89 gram, sedangkan tanaman jagung manis yang memiliki jumlah daun 9,78 menghasilkan berat tongkol 
tanpa kelobot 304,56 gram (Surtinah, 2008). Hasil Penelitian memperlihatkan bahwa tinggi tanaman jagung 216,35 Cm, lebar daun $10,36 \mathrm{Cm}$, panjang daun 95,75 $\mathrm{Cm}$, menghasilkan berat tongkol tanpa kelobot 239,38 gram. Dan penelitian (Hayati, 2006) mendapatkan bahwa dengan tinggi tanaman 118,29 $\mathrm{cm}$ diperoleh berat tongkol $245,13 \mathrm{~cm}$, sedangkan pada tinggi tanaman 149,10 cm diperoleh berat tongkol 255,47 cm (Lidar, S., dan Surtinah, 2012). Panjang dan berat tongkol berkelobot berbeda tidak nyata yang dilaporkan dari suatu penelitian, fenomena ini bisa saja disebabkan oleh faktor vegetatif tanaman jagung manis dan faktor lingkungan yang diasumsikan homogen (Surtinah., 2013).

(Zulkifli, dan Herman, 2012), melaporkan bahwa dengan luas daun tanaman 79,57 $\mathrm{cm}^{2}$ diperoleh panjang tongkol 20,73 cm, sedangkan dengan luas daun 75,47 $\mathrm{cm}^{2}$ diperoleh panjang tongkol jagung manis 20,82 cm. Hasil penelitian yang dilakukan oleh (Dinariani, Y.B.S. Heddy, dan B. Guritno, 2014) dengan jumlah daun 12 helai diperoleh berat tongkol tanpa kelobot 189,00 gram, dan pada jumlah daun 10,89 diperoleh berat tongkol tanpa kelobot 13,99 gram.

Penelitian yang dilakukan oleh (Made, 2010) diperoleh tinggi tanaman jagung manis yang tertingi yaitu $217,10 \mathrm{~cm}$ dengan berat tongkol 184,86 gram, dan tinggi tanaman 216,12 $\mathrm{cm}$ diperoleh berat tongkol 171,70 gram. (Sirajuddin, M., S.A. Lasmini, 2010) melaporkan bahwa tanaman jagung yang diberi perlakuan pupuk Nitrogen dan tebal mulsa yang berbeda menghasilkan tinggi tanaman jagung manis tertinggi yaitu $175,29 \mathrm{~cm}$, dengan berat tongkol 247 gram, sedangkan tanaman yang diberi nitrogen dengan takaran yang lebih rendah dan ketebalan mulsa yang sama, tinggi tanaman jagungnya adalah 166,71 $\mathrm{cm}$, dan berat tongkolnya adalah 250 gram.

(Wijaya, S. dan Wahyuni, 2007) mendapatkan tinggi tanaman tertinggi 222,7 cm dengan berat tongkol tanpa kelobot 185 gram dan berbeda tidak nyata dengan perlakuan pupuk Kalium dalam dosis yang lebih tinggi. (Surtinah, Susi, N., Lestari, S.U., 2016) melaporkan bahwa Varietas Sugar 75 dengan lebar daun 10,33 cm menghasilkan berat tongkol tanpa kelobot $271 \mathrm{~g}$, varietas Bintang Asia dengan lebar daun $11,33 \mathrm{~cm}$ menghasilkan berat tongkol tanpa kelobot 317,33 g, varietas Bonanza dengan lebar daun $10,50 \mathrm{~cm}$ menghasilkan berat tongkol tanpa kelobot 248,67 g, varietas Sagita Sweet dengan lebar daun $09,50 \mathrm{~cm}$ menghasilkan berat tongkol tanpa kelobot $259 \mathrm{~g}$, dan varietas Master Sweet dengan lebar daun 10,67 menghasilkan berat tongkol tanpa kelobot 219,67 g.

Tujuan penelitian ini adalah Untuk mengetahui hubungan pertumbuhan organ vegetatif terhadap produksi jagung manis, dan untuk mendapatkan informasi apakah organ vegetatif tanaman jagung manis dalam suatu penelitian perlu dijadikan peubah yang harus diamati.

\section{METODE PENELITIAN}

Lokasi penanaman adalah di kebun percobaan Fakultas Pertanian Unilak, dengan topografi datar dengan ketinggian $20 \mathrm{~m} \mathrm{dpl}$, jenis tanah PMK. Penelitian dilaksanakan secara eksperimen dengan menggunakan rancangan lingkungan acak lengkap dengan 4 kali ulangan 
dan rancangan perlakuan yaitu enam varietas jagung manis : v1= sugar 75 ; v2 = Bintang Asia; v3 = Bonanza; v4 = sagita Sweet; v5 = Master sweet; v6 = Premium. Data primer dianalisis dengan menggunakan Regresi polinomial. Pengolahan tanah dilakukan dua kali. Pengolahan tanah yang pertama bertujuan untuk membalikkan tanah dan menghancurkan bongkahanbongkahan tanah agar lebih gembur. Pengolahan tanah yang ke dua bertujuan untuk memperbaiki aerasi tanah, sehingga kehidupan mikroorganisme tanah menjadi lebih baik. Pembuatan plot sebanyak 24 unit percobaan (plot) dengan ukuran $120 \times 100 \mathrm{~cm}$, dengan jarak antar plot $75 \mathrm{~cm}$. Pupuk kandang diberikan bersamaan dengan pengolahan tanah kedua, dua minggu sebelum tanam dengan dosis 40 ton/ha ( $6 \mathrm{~kg} /$ plot $)$.

Benih ditanam dengan kedalaman lebih kurang $3 \mathrm{~cm}$ dengan jarak tanam 40 × $50 \mathrm{~cm}$. Setiap lubang tanam dimasukkan 3 benih, dan hanya satu tanaman yang dibiarkan tumbuh besar. Pemberian pupuk NPK diberikan 3 kali yaitu pada waktu tanam dengan dosis $3 \mathrm{~g} /$ tanaman. Pupuk dibenamkan ke dalam tanah sedalam $5 \mathrm{~cm}$ disebelah lubang tanam dengan jarak $5 \mathrm{~cm}$, kemudian ditutup tanah. Pada saat tanaman berumur 3 minggu setelah tanam dengan dosis $5 \mathrm{~g} /$ tanaman, dan $5 \mathrm{~g} /$ tanaman pada saat tanaman berumur 6 minggu, pupuk dibenamkan dengan jarak $10 \mathrm{~cm}$ dari tanaman dengan kedalaman $7 \mathrm{~cm}$.

Pencegahan serangan hama digunakan Decis 2,5 EC dengan konsentrasi $2 \mathrm{ml} / \mathrm{l}$ air dan untuk pencegahan penyakit digunakan Dithane M-45 dengan konsentrasi 2 $\mathrm{g} / \mathrm{l}$ air, penyemprotan dilakukan pada saat tanaman berumur 4 dan 8 minggu setelah tanam. Tanaman disiram dua kali dalam sehari yaitu pagi dan sore hari dengan volume air yang sama yaitu 10 liter/plot, dan pemberian disesuaikan dengan umur tanaman. Tanaman jagung manis yang tumbuh dipilih yang vigor pertumbuhannya, dan hanya disisakan satu tanaman/lubang tanam. Penyiangan dilakukan satu minggu sekali dengan cara mencabut gulma-gulma yang tumbuh di plot dan diantara plot percobaan. Jagung manis dipanen pada umur 65 hari dihitung dari saat tanam.

Pengamatan dilakukan terhadap, panjang daun $(\mathrm{cm})$, Jumlah Daun (helai), Lebar daun (cm), dan Kandungan gula biji (\%).

\section{HASIL DAN PEMBAHASAN}

\section{Hasil Penelitian}

Hasil uji statistik dengan menggunakan regresi polinomial terhadap data dari pengukuran parameter yang diamati disajikan dalam beberapa tabel berikut ini:

Tabel 1. Hasil analisis varians terhadap korelasi pertumbuhan dengan kadar gula biji.

\begin{tabular}{|l|c|c|c|}
\hline \multicolumn{1}{|c|}{ Parameter } & F hitung & F tabel & Keterangan \\
\hline Tinggi Tanaman $(\mathrm{cm})$ & 4,25 & 9,55 & Pengaruh tidak nyata \\
\hline Jumlah daun (helai) & 7,35 & 9,55 & Pengaruh tidak nyata \\
\hline Panjang daun $(\mathrm{cm})$ & 5,23 & 9,55 & Pengaruh tidak nyata \\
\hline Lebar daun $(\mathrm{cm})$ & 0,19 & 9,55 & Pengaruh tidak nyata \\
\hline
\end{tabular}


Pembahasan

\section{Korelasi antara tinggi tanaman dengan kadar gula \\ biji}

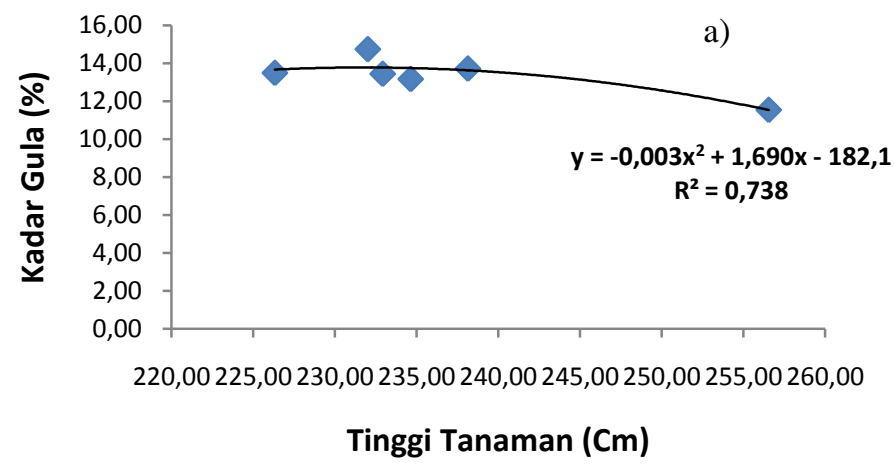

Korelasi antara jumlah daun dengan kadar gula biji

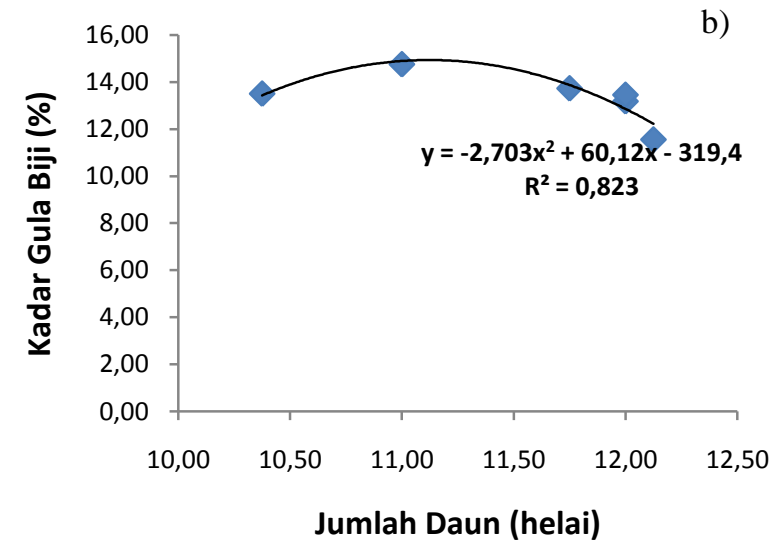

Korelasi antara panjang daun dengan kadar gula biji

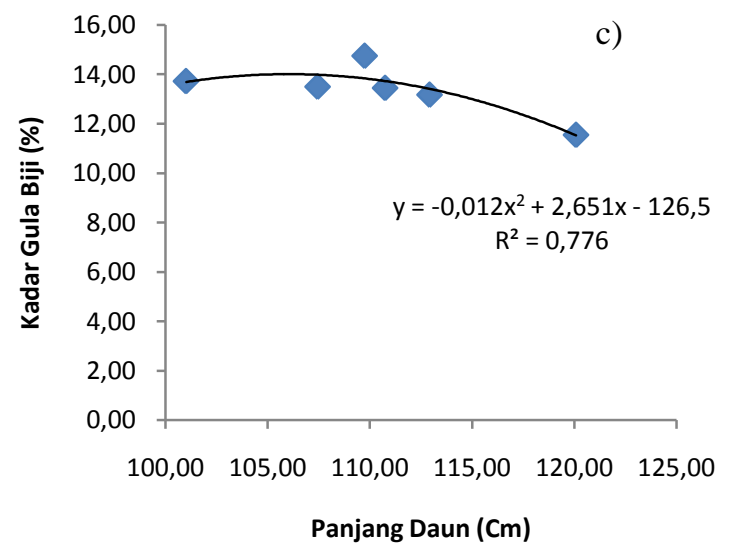

Jurnal Ilmiah Pertanian Vol, 13 No. 2, Februari 2017 | 76 


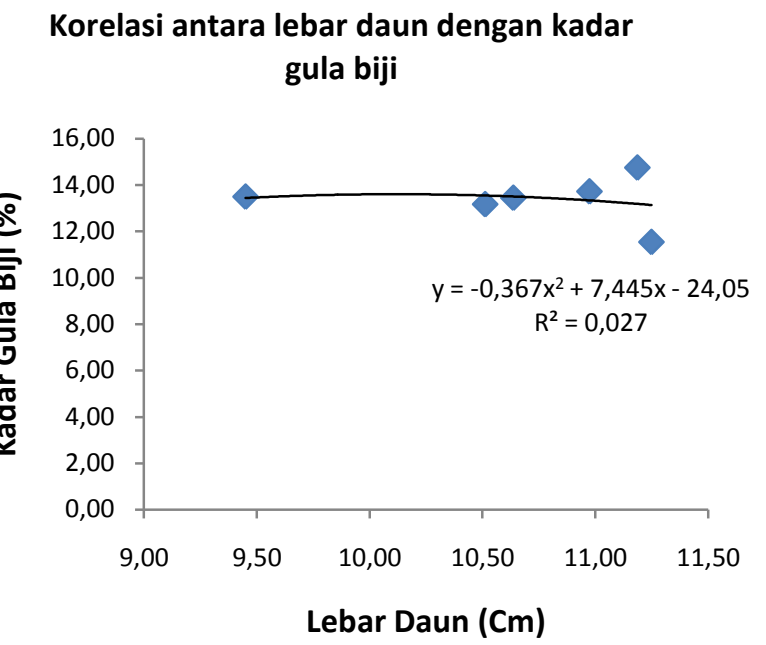

Gambar a) Korelasi antara tinggi tanaman dengan kadar gula biji; b) Korelasi antara jumlah daun dengan kadar gula biji ; c) Korelasi antara panjang daun dengan kadar gula biji; d) Korelasi antara lebar daun dengan kadar gula biji.

Tinggi tanaman, jumlah daun, dan panjang daun tanaman jagung manis dapat digunakan sebagai acuan untuk menjelaskan peningkatan kadar gula biji jagung manis. Hal ini berdasarkan nilai $\mathrm{R}^{2}=73,8 \%$ untuk tinggi tanaman merupakan nilai yang menunjukan hubungan yang kuat, dan $\mathrm{R}^{2}=82,3 \%$ menunjukan hubungan yang sangat kuat untuk jumlah daun, dan $\mathrm{R}^{2}=77,6 \%$ menunjukan hubungan yang kuat untuk panjang daun jagung manis terhadap kadar gula biji jagung manis.

\section{KESIMPULAN}

1. Pertumbuhan organ vegetatif seperti tinggi tanaman, jumlah daun, dan panjang daun meunjukan hubungan yang erat dengan kadar gula biji jagung manis.

2. Lebar daun tidak memberikan hubungan yang kuat dalam memacu perkembangan kadar gula biji jagung manis sehingga tidak perlu diamati.

\section{DAFTAR PUSTAKA}

Dinariani, Y.B.S. Heddy, dan B. Guritno. (2014). Kajian Penambahan Pupuk Kandang Kambing dan Kerapatan Tanaman yang Berbeda pada Pertumbuhan dan Hasil Jagung Manis (Zea mays saccharata, Sturt). Jurnal Produksi Tanaman Vol. 2 (2) , 128-136.

Hayati, N. (2006). Pertumbuhan dan Hasil jagung Manis (Zea mays saccharata, Sturt) pada berbagai Waktu Aplikasi Bokashi Limbah Kulit Buah Kakao dan Pupuk Anorganik. Jurnal Agroland, Vol. 13 (3): , 256-259.

Lidar, S., dan Surtinah. (2012). Respon Tanaman Jagung Manis (Zea mays saccharata, Sturt) Akibat Pemberian Tiens Golden Harvest. Jurnal Ilmiah Pertanian, Vol. 8 (2) , 1-5.

Made, U. (2010). Respons Berbagai Populasi Tanaman Jagung Manis (Zea mays saccharata, 
Sturt) terhadap Pemberian Pupuk Urea. Jurnal Agroland, Vol 17 (2), 138-142.

Sirajuddin, M., S.A. Lasmini. (2010). Respon Pertumbuhan dan Hasil Jagung Manis (Zea mays saccharata, Sturt) pada Berbagai Waktu Pemberian Pupuk Nitrogen dan Ketebalan Mulsa Jerami. Jurnal Agroland, Vol. 17 (3) , 184191.

Surtinah. (2005). Hubungan Pemangkasan Organ Bagian Atas Tanaman jagung (Zea mays) dan Dosis Urea terhadap Pengisian Biji. Jurnal Ilmiah Pertanian , 27-35.

Surtinah. (2013). Pengujian Tiga Varietas Jagung Manis (Zea mays saccharata, Sturt) di Rumbai Kota Pekanbaru. Jurnal Ilmiah Pertanian, Vol. 1 (1) Edisi Khusus , 1-10.

Surtinah, Susi, N., Lestari, S.U. (2015). Komparasi Tampilan dan Hasil Lima Varietas Jagung Manis (Zea mays saccharata, Sturt) di Kota
Pekanbaru. Pekanbaru. Jurnal Ilmiah Pertanian, Vol. 13 (1), $31-37$.

Surtinah. (2013). Pengujian Tiga Varietas Jagung Manis (Zea mays saccharata, Sturt) di Rumbai Kota Pekanbaru. Jurnal Ilmiah Pertanian, Vol. 1 (1) Edisi Khusus , 1-9.

Surtinah. (2008). Waktu Panen yang Tepat Menentukan Kandungan Gula Biji Jagung Manis (Zea mays saccharata, Sturt). Jurnal Ilmu Pertanian, Vol. 2 (2): , 17.

Wijaya, S. dan Wahyuni. (2007). Respon Tanaman Jagung Manis (Zea mays saccharata, Sturt) Kultivar Hawaian Super Sweet pada Berbagai Takaran Pupuk Kalium . Jurnal AGRIJATI Vo. 6 (1) , 42-47.

Zulkifli, dan Herman. (2012). Respon Jagung Manis (Zea mays saccharata, Sturt) terhadap Dosis dan Jenis Pupuk Organik. Jurnal Agroteknologi, Vol. 2 (2) , 3336. 